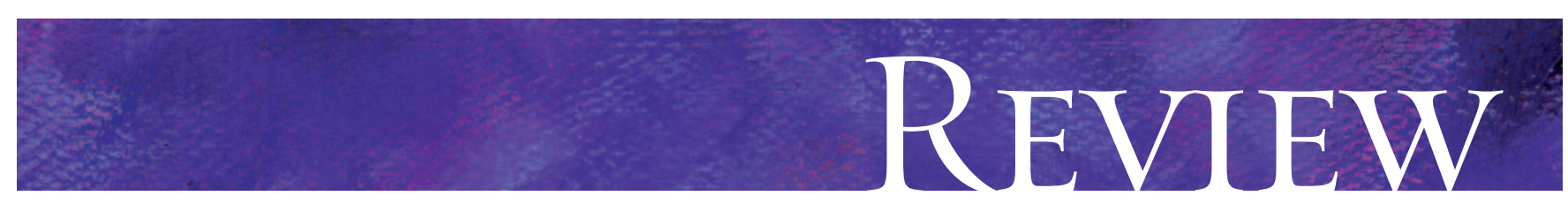

\title{
Prostate-specific antigen in the early detection of prostate cancer
}

\author{
Ian M. Thompson, Donna P. Ankerst
}

$\infty \quad$ See related article page 1850

\section{ABSTRACT}

Throughout Canada, the United States and much of Europe, prostate-specific antigen (PSA) screening for prostate cancer has proliferated over the past 2 decades, leading to dramatic increases in detection rates of prostate cancer. Although it has unquestionably led to increased detection of cancer and a migration to lower-stage and-volume tumours, it is still unknown whether PSA screening significantly reduces mortality from prostate cancer. Often thought to be dichotomous (i.e., either normal or elevated), PSA measurements actually reflect cancer risk, with the risks of cancer and of aggressive cancer increasing with the level of PSA. The recently developed risk calculator from the Prostate Cancer Prevention Trial, which integrates family history of prostate cancer, digital rectal examination findings, PSA test result, age, ethnicity, and history of a prior prostate biopsy with a negative result, allows clinicians to assess a patient's individual risk of cancer. This risk should be examined in the context of a patient's life expectancy and comorbidity as well as his concern about the possibility of prostate cancer. The terms "normal" and "elevated" as descriptors of PSA results should be abandoned.

CMAJ 2007;176(13):1853-8

$\mathrm{E}$ arly diagnosis and treatment of prostate cancer was first suggested a century ago. ${ }^{1}$ It was observed that, when detected early, most prostate cancers can be treated and cured, whereas when prostate cancer is diagnosed after symptoms have appeared, metastases are generally present. Like most intuitive notions, that early detection reduces population mortality is unproven. ${ }^{2}$ Prostate cancer screening is currently being tested in 2 large randomized clinical trials, one in the United States ${ }^{3}$ and the other in Europe. ${ }^{4}$ The US trial, an ongoing study that has tested screening for lung, colorectal and ovarian cancer sites as well as prostate, has enrolled 155000 women and men 55-74 years of age. The European study is a 7 -country trial that enrolled I63 126 men between 1992 and 2001 and randomly assigned them to screening tests versus community patterns of care. The results of these studies may require several more years to complete. Advocates of screening point to an increased rate of discovery of lower-stage cancer, a fall in the incidence of metastatic disease and a reduction in related mortality about 5 years after widespread prostate-specific antigen (PSA) screening was begun in the United States. ${ }^{5}$ Critics point to evidence of high rates of overdetection: the lifetime risk of diagnosis is currently $18 \%$, whereas that for death from prostate cancer is $3 \%$. Overdetection leads to overtreatment, with the resultant costs, side effects, complications and increased patient anxiety that are associated with any of the wide-ranging current treatments. ${ }^{6}$

Most men who receive a diagnosis of prostate cancer after PSA screening are found to have clinically localized disease and are offered a range of treatments, which include radiotherapy, surgery or simple observation (i.e., watchful waiting). In addition to cancer control, important issues around treatment include urinary, sexual and bowel function. Unfortunately, comparing the cancer-control outcomes of the various therapies is difficult because of the paucity of randomized clinical trials, a migration toward diagnoses at a lower clinical stage of disease and changes in tumour grade assignment over time. Only one sufficiently powered randomized clinical trial has compared treatments head-to-head. In this study, ${ }^{7} 695$ men with clinically localized prostate cancer were randomly assigned to watchful waiting or radical prostatectomy. The surgery group had significantly lower risks of local progression, metastatic disease, death from cancer and overall death.

Despite debate about screening, in many countries a PSA test and digital rectal examination are part of a routine medical check-up. Although the Canadian Task Force on Preventive Health Care (formerly called the Canadian Task Force on the Periodic Health Examination) currently finds insufficient evidence to promote screening for the early detection of prostate cancer in asymptomatic men, and both the Canadian Urological Association and the Prostate Cancer Alliance have recommended that it be performed only after detailed discussion of the pros and cons between doctor and patient, a recent nationwide survey indicated that almost half of Canadian men over 50 years of age reported receiving PSA screening during their lifetime, $72 \%$ of these during the preceding year. ${ }^{8-11}$ Awareness, utilization and knowledge of the pros and cons of PSA screening, however, vary considerably by region in Canada, ${ }^{12,13}$ and physicians and patients alike would benefit from clarification of the information currently available about this screening method. ${ }^{14}$ 


\section{Issues in screening and biomarker evaluation}

\section{The goal of screening}

The goal of screening is to identify a disease at a stage in its natural history where treatment can be implemented to prevent death or suffering. ${ }^{15,16}$ Achieving that for prostate cancer is problematic because of the variable natural history of the disease. Autopsy studies have found that $27 \%$ of men in their 30 and $34 \%$ of men in their 40 s have histologic evidence of this disease. ${ }^{17}$ These rates, which increase even further over a man's lifetime, must be contrasted with a current lifetime risk of disease diagnosis in the United States of $18 \%$ (up from $8 \%$ before the advent of PSA screening) and a lifetime risk of death from prostate cancer of $3 \%{ }^{18}$ These data suggest both overdetection of some prostate cancers and a failure to diagnose some cases of aggressive disease at a stage that is sufficiently early to achieve a cure.

\section{Measurement of performance of screening tests}

The ideal screening test for prostate cancer should be dichotomous, with a result of either "cancer present" or "cancer not present." In reality, the results of screening tests are continuous. Their performance in classifying subjects can be measured in several ways. One method reports sensitivity (i.e., the fraction of diseased men who test positive) and specificity (the fraction of nondiseased men who test negative). These measures allow an interpretation of trade-offs between maximizing the number of prostate cancers detected (sensitivity, equivalent to minimizing the false-negative rate, which is I sensitivity) and minimizing the number of false-positive tests ( $\mathrm{I}$ - specificity). In prostate cancer screening, a test must have a false-positive rate that is low (e.g., $<20 \%$ ) to be considered sufficiently ethically sound and economically feasible for widespread use; a cut-off value is then chosen that maximizes the sensitivity of the test under this constraint. Unfortunately, as will be described, the leading biomarker for prostate cancer, PSA, has a low sensitivity: about $40 \%$.

A shortcoming of the use of sensitivity and specificity to evaluate tests is that these measures do not convey the full informational content and complexity of continuous screening tests. Tests based on biologic markers must be assigned a cut-off level to produce a dichotomous (positive or negative) result. Likelihood ratios, which report how much more likely a person with disease is to have a specific test result than a person without, have a useful clinical interpretation as a risk ratio and do not require the dichotomization of continuous measures. However, a likelihood ratio is a single number that cannot be broken into the false- and true-positive rates of interest to public policy-makers. ${ }^{19}$

\section{Biases in the evaluation of biomarker performance}

An error common throughout the history of prostate cancer screening might be described as a self-fulfilling prophecy: If you don't look for it, you won't find it. In the late ig8os, with- out preliminary validation studies to ascertain test performance, a cut-off level of $4.0 \mathrm{ng} / \mathrm{mL}$ was widely adopted, and virtually no patients with levels less than that underwent biopsy. As a result, for almost 2 decades prostate cancer was generally thought to be almost nonexistent at PSA levels under $4.0 \mathrm{ng} / \mathrm{mL}$. As we later found, this was incorrect and PSA results, like those of other markers, are not dichotomous. ${ }^{20}$ Because of the failure to verify the true prostate-cancer status of men with low PSA concentrations and the subsequent exclusion of these men from formal evaluations of the operating characteristics of the test, many of the earlier reports on the test's sensitivity and specificity were upwardly biased. ${ }^{21}$

Repeat biopsies also exacerbate this verification bias. When a biomarker is tested, there are positive test results for individual patients in whom, at biopsy, no disease is found. This is a major problem for this subpopulation: men screened for prostate cancer who test positive for a biomarker but have a negative biopsy result are likely to undergo multiple repeat biopsies during follow-up. Rarely are biomarker studies updated with respect to these later events. A more insidious predictive bias involves those people whose biomarker (e.g., PSA) findings are elevated. These men often undergo a biopsy and, if the result is negative, also often undergo many biopsies over the ensuing years. Because the likelihood of cancer detection is directly related to the degree of prostate sampling, an elevated PSA level leads to repeated biopsies until cancer is found. In contrast, a PSA measurement in the normal range results in less frequent ascertainment and a higher risk of a missed cancer diagnosis.

Another bias that directly affects cancer detection involves the biopsy method. The posterior region of the prostate gland is where most cancers arise; biopsies are directed (somewhat randomly) to sample from that area. The average number of biopsy cores taken varies by clinical practice. In initial screening studies, investigators obtained 4 biopsy cores. In 1989 , this increased to 6 cores; more recently, numbers have ranged from 12 to 24 cores. This increased number of biopsy cores dramatically increases the likelihood of cancer detection. ${ }^{22-24}$ Moreover, the size of the prostate gland (i.e., its volume) varies from patient to patient. Successful cancer detection is more likely in a smaller than a larger prostate; this produces a bias in the evaluation of PSA screening that is related to the presence and size of the cancer as well as the size of the prostate itself. $^{25}$

\section{Prostate-specific antigen}

This biomarker, a human kallekrein secreted by prostate epithelial cells, is a normal component of the ejaculate. These epithelial cells are also the progenitor cells of prostate adenocarcinoma.

The adoption of PSA screening in the United States could not have been predicted from the initial reports. A substantial overlap in values was found between patients with and without cancer. Initial recommendations for the upper limit of the normal range varied from 2.5 to $24 \mathrm{ng} / \mathrm{mL} .{ }^{26,27}$ With about $8 \%$ of the population having a PSA level above $4.0 \mathrm{ng} / \mathrm{mL}$, for whom the lifetime risk of disease is about $8 \%$ (at that time) 
and for whom the risk of cancer at prostate biopsy was about $25 \%$, PSA screening became a fait acompli, especially after the US Medicare decision to pay for one such screening test per man per year. ${ }^{28-31}$

In the late I990s, reports suggested that the risk of prostate cancer at biopsy at PSA levels of $2.5-4.0 \mathrm{ng} / \mathrm{mL}$ was similar to that at $4-\mathrm{Io} \mathrm{ng} / \mathrm{mL} .{ }^{32,33}$ In 2003 , we reported the results of the Prostate Cancer Prevention Trial, ${ }^{34}$ a study comparing finasteride with placebo. In this study, 9459 men who received placebo had an annual PSA test and a digital rectal examination; biopsy was recommended if the PSA level exceeded $4.0 \mathrm{ng} / \mathrm{mL}$ or if digital rectal examination results were abnormal. After 7 years, all participants not found to have prostate cancer were recommended to undergo biopsy. A surprising cancer prevalence was found in what was thought to be a low-risk group. In the placebo group, of the men whose PSA levels remained below $4.0 \mathrm{ng} / \mathrm{mL}$ and whose annual rectal examination results were consistently normal ( $n=2950$ ) - a group that would previously have been regarded as disease free - $15 \%$ were found to have prostate cancer and of these, $15 \%$ had high-grade prostate cancer (Fig. $\mathrm{I},{ }^{20} \mathrm{Box} \mathrm{I}$ ). Even within the $0-4.0 \mathrm{ng} / \mathrm{mL}$ interval, the PSA level was a continuously increasing marker of prostate cancer risk, with no boundary below which no prostate cancer was found.

Our next investigation explored a notion that had been previously held: high-grade prostate cancer cells do not make PSA. ${ }^{35}$ We examined 5587 men in the placebo group, all of whom eventually underwent prostate biopsy. ${ }^{36}$ We found that, for cancer detection, the area under the receiver-operating characteristic curve (a measure of the performance of a test; the area under the receiver-operating characteristic curve of the toss of a coin has a value of 0.5 , whereas that for any test

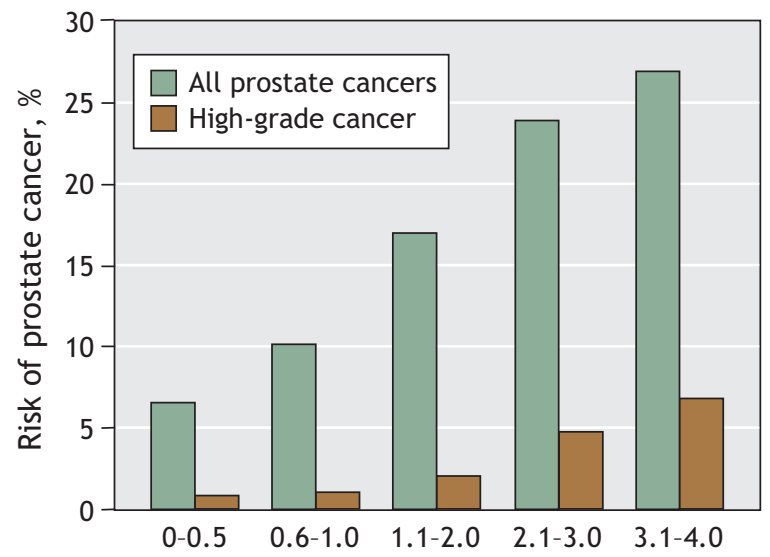

Prostate-specific antigen concentration, $\mathrm{ng} / \mathrm{mL}$

Fig. 1: Risk of prostate cancer by range of prostate-specific antigen level. Data are from control subjects involved in the Prostate Cancer Prevention Trial (N EnglJ Med 2004;350:2239$46)^{20}$ who had normal digital rectal examination results and prostate-specific antigen levels $<4.0 \mathrm{ng} / \mathrm{mL}$ throughout the 7 year study, as well as an end-of-study biopsy $(n=2950)$. Highgrade cancer refers to a Gleason score $\geq 7$.
Box 1: Prostate cancer grade: the Gleason scoring system

- This grading system ranges from 1 (the least aggressive) to 5 (the most aggressive histologic pattern).

- Because tumours are often heterogeneous and multifocal, a biopsy needle can sample multiple patterns. The primary (most common) pattern is stated first, with the secondary pattern listed second in an " $\mathrm{x}+\mathrm{y}$ " reporting format (e.g., Gleason 3+4).

- Grades for both patterns are added together to give the Gleason score.

- More information is revealed if the most common and the second most common values are provided separately; for example, a 3 [most common] + 4 [second most common] grade is less aggressive than a 4 [most common] + 3 [second most common] grade, even though the overall Gleason score is 7 in either case.

- The range of possible Gleason scores or combined grades is from 2 to 10.

- Gleason patterns 1 and 2 are uncommon; therefore, most Gleason scores that are reported range from 5 to 10 .

with $100 \%$ sensitivity at all specificities has an area of I.0) for PSA screening was 0.68 (95\% confidence interval [CI] o.670.69 ), a reasonable level of test performance. Moreover, although we observed high-grade tumours in many patients whose PSA levels were low, the test performed even better at detecting high-grade disease (Fig. 2): for a Gleason tumour score of 7 or more, the area under the receiver-operating characteristic curve was 0.78 (95\% CI $0.75-0.82$ ); for a Gleason score of 8 or more, 0.83 ( $95 \% \mathrm{CI} 0.76-0.89$ ).

Unfortunately the receiver-operating characteristic curve does not tell the whole story. Table I shows the PSA levels as well as sensitivities, specificities and likelihood ratios..$^{36}$ If the goal in screening a patient for prostate cancer is to be $80 \%$ certain that the clinician does not miss cancer, a PSA cut-off of about I.I ng/mL must be used and will result in biopsy of almost $60 \%$ of men who do not have prostate cancer. For detection of Gleason $\mathrm{x} 8$ or higher disease, the $80 \%$ sensitivity level allows the physician to use a PSA of $2.6 \mathrm{ng} / \mathrm{mL}$ and the false-positive rate is cut by more than half. Unfortunately, focusing only on high-grade disease ignores recent findings ${ }^{37}$ that about a third of men who died of prostate cancer had a Gleason disease score at diagnosis of 6 or less.

\section{Other biomarkers}

Studies have reported good operating characteristics of other PSA-related measures; such findings suggest that they outperform PSA. A frequent example is PSA velocity: a rising PSA is often used as an indication for prostate biopsy. We have demonstrated that, although PSA velocity is an indicator of risk, when the absolute value of PSA is incorporated into the analysis, velocity provides no independent predictive value for cancer risk..$^{38}$ Updated guidelines based on recommended new markers that did not undergo due comparison to PSA may ultimately not improve prostate cancer screening. 


\section{Digital rectal examination}

Herein we include digital rectal examination as a measure of risk. Not truly a biomarker, the procedure may best be characterized as either a risk measure or a biomeasure. The range of findings from this examination have differing predictive values for prostate cancer. Unfortunately, the test is not standardized and varies widely among physicians, ${ }^{39,40}$ as reflected by large-scale population studies in which the rate of abnormal findings from digital rectal examination varied from $3 \%$ to $12 \% .{ }^{41,42}$ It is generally accepted that any abnormality found during digital rectal examination should prompt prostate biopsy, and that this examination has predictive value for prostate cancer diagnosis that is independent of that of PSA. ${ }^{27}$

There is active research in the early validation stages for other prostate cancer biomarkers, including $\mathrm{PCA}_{3}$, in which the messenger RNA from the gene (which is highly expressed in prostate cancer) can be measured in urine. ${ }^{43,44}$ Another commonly used marker is the percentage of free PSA, in which the ratio of free to total PSA is measured. ${ }^{45}$ Protein profiling with surface-enhanced laser desorption or ionization mass spectrometry has been found to have a sensitivity of $83 \%$ and a specificity of $97 \%$ for prostate cancer, ${ }^{46}$ but the technique has many technologic, replication and validation issues that could hamper its general use.

\section{Creating a clinical decision-making tool}

In addition to PSA and digital rectal examination findings, there are other risk factors of importance, such as age, family history of prostate cancer, ethnicity, other hereditary and environmental factors and attributes (e.g., diet, body mass index, supplement use), and a prior biopsy with negative results for cancer. Historically, physicians estimated a patient's risk based on clinical experience and anecdote as well as an understanding of the medical literature. Unfortunately, experiential estimates are often inaccurate. ${ }^{47}$
Table 1: Test sensitivities, specificities and likelihood ratios $(\mathrm{LR})^{*}$ by serum prostate-specific antigen (PSA) concentration for a prostate biopsy result that is positive for cancer

\begin{tabular}{|c|c|c|c|c|c|c|}
\hline \multirow{2}{*}{$\begin{array}{l}\text { PSA, } \\
\mathrm{ng} / \mathrm{mL}\end{array}$} & \multicolumn{3}{|c|}{ Prostate cancer, any grade } & \multicolumn{3}{|c|}{ Gleason grade $\geq 8$ cancer } \\
\hline & Sensitivity & Specificity & LR & Sensitivity & Specificity & LR \\
\hline 1.1 & 83.4 & 38.9 & 1.36 & 94.7 & 35.9 & 1.48 \\
\hline 2.1 & 52.6 & 72.5 & 1.91 & 86.0 & 65.9 & 2.52 \\
\hline 2.6 & 40.5 & 81.1 & 2.14 & 78.9 & 75.1 & 3.17 \\
\hline 3.1 & 32.2 & 86.7 & 2.42 & 68.4 & 81.0 & 3.60 \\
\hline 4.1 & 20.5 & 93.8 & 3.31 & 50.9 & 89.1 & 4.67 \\
\hline 6.1 & 4.6 & 98.5 & 3.07 & 26.3 & 97.5 & 10.52 \\
\hline 10.1 & 0.9 & 99.7 & 3.00 & 5.3 & 99.5 & 10.60 \\
\hline
\end{tabular}

*Data are from the Prostate Cancer Prevention Trial (JAMA 2005;294:66-70). ${ }^{36}$

To investigate how these risk factors could be integrated, we evaluated 5519 men from the placebo group of the Prostate Cancer Prevention Trial who underwent prostate biopsy and had a PSA test and digital rectal examination within the year preceding the biopsy, who had at least 2 previous annual PSA measures and for whom we had data on age, ethnicity, previous biopsy results and family history of prostate cancer. ${ }^{27}$ Using logistic regression, we found 4 variables to be independently and significantly associated with the presence of prostate cancer in the biopsy sample (Fig. 3): PSA level, ${ }^{20}$ family history of prostate cancer, an abnormal result from a digital rectal examination and (inversely) a previous negative biopsy result - men with a previous negative biopsy result had a significantly and independently reduced risk of cancer at biopsy. Predictors of high-grade (Gleason score $\geq 7$ ) cancer found at biopsy included PSA level, abnormal findings from a digital rectal examination, older age and African-American ancestry, whereas a previous negative biopsy result was associated with a lower risk of high-grade cancer (Fig. 3). To help clinicians and patients use the findings from this analysis, ${ }^{38}$ we devel-

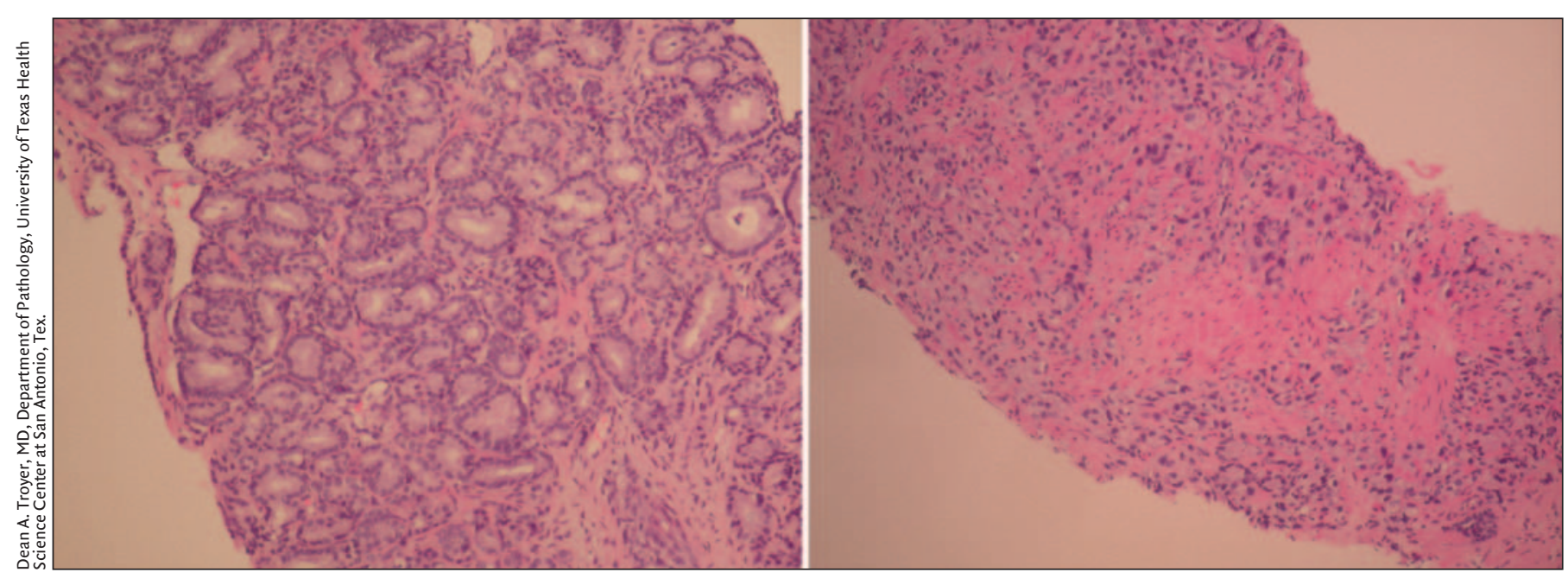

Fig. 2: Micrographs of thin slices of prostate cancer tissue. Left, a mixture of two grade 3 patterns: Gleason grade $3+3$ (a score of 6 ). Right, the most aggressive histologic pattern: Gleason score 10. 


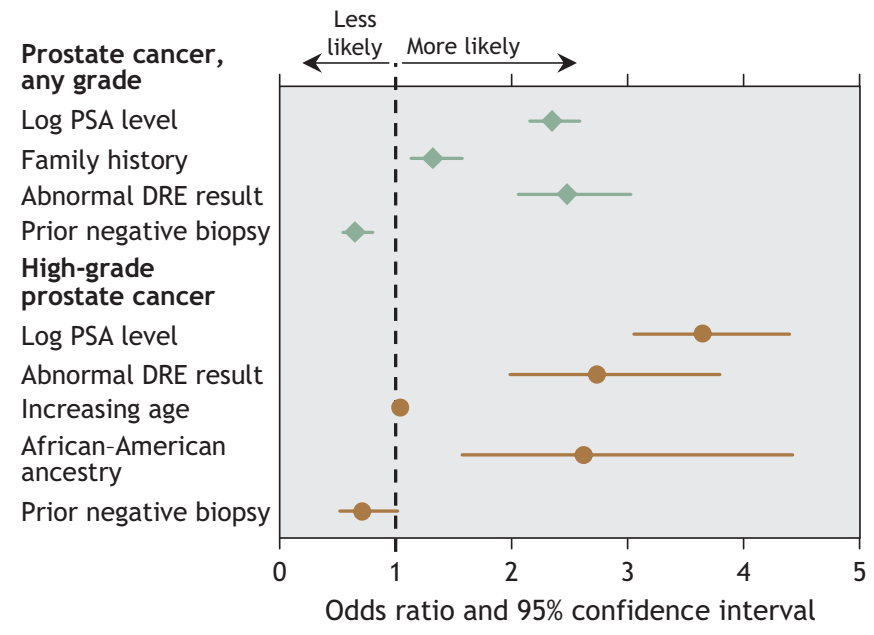

Fig. 3: Forest plot of risk factors for prostate cancer and for high-grade prostate cancer (Gleason score $\geq 7$ ) if a prostate biopsy is performed. PSA = prostate-specific antigen, DRE $=$ digital rectal examination.

oped a risk calculator (available at www.compass.fhcrc.org /edrnnci/bin/calculator/main.asp) that uses these variables to provide estimates of risk of prostate cancer and of high-grade disease along with 95\% confidence intervals. This calculator has been independently validated both within the Prostate Cancer Prevention Trial and on external populations. ${ }^{48}$

\section{Counselling patients}

A physician should review with a patient that a prostate biopsy has 3 potential outcomes (summarized in Table 2). The first is a negative biopsy (no cancer). The benefit of this result is that the patient is informed of no current evidence of prostate cancer. It must also be recognized that the biopsy was, in retrospect, unnecessary; that a tumour could have been missed; and that prostate cancer could develop later. Another potential outcome is high-grade (aggressive) prostate cancer (Gleason score $7-$ Io). The benefit of this result is that early diagnosis may give the patient an opportunity for curative treatment. Two disadvantages are that the disease may be incurable at diagnosis or (although uncommon) could be indolent and destined to cause no problems during the patient's lifetime. The remaining possible result is a less aggressive prostate cancer. Some of these tumours cause illness and death, which early treatment may prevent. More commonly, based on the rate of diagnosis we found in the Prostate Cancer Prevention Trial, slower-growth tumours will be detected for which treatment is unnecessary. Unfortunately, because it is not possible at this time to distinguish with certainty indolent tumours from morbid ones, most men with this third outcome receive treatment with the intention to cure.

Ideally, patients should attach different weights to the benefits and risks of the 3 outcomes and decide, based on their personal priorities and risk aversions, whether or not to undergo biopsy. It is likely that patients will rely on the advice and experience of the treating physician; for this reason, counselling clinicians must be fully aware of the entire range of prostate cancer outcomes.

Once a decision is made to use PSA tests for screening, the Prostate Cancer Prevention Trial risk calculator can be used to incorporate a patient's PSA measurements with all other risk factors into an individual estimate of prostate cancer risk. The estimates of risk (both of all grades of prostate cancer and of high-grade cancer) and their consequences can then be discussed with the patient along with the advantages and disadvantages of this knowledge and subsequent treatment. $\mathrm{Pa}-$ tients can then use their own priorities on disease, treatment and functional changes after treatment to decide whether to proceed with a biopsy. Ultimately, this counselling process will then lead to a better-informed patient if a biopsy is performed and cancer is detected.

\section{Conclusion}

It is unproven that population-wide screening with PSA testing will reduce death and illness from prostate cancer. Nonetheless, this test is commonly ordered by physicians across North America. If screening is requested by an asymptomatic man, the clinician should inform him of his risk of prostate cancer, incorporating findings for all the known risk factors for the disease - family history, age, ethnicity, digital rectal examination findings, PSA level and the results of any previous prostate biopsy. Based on his own risk and understanding of the consequences of a cancer diagnosis, the patient can best determine whether a prostate biopsy would be appropriate.

Table 2: A summary of the benefits and disadvantages of the 3 possible outcomes of a prostate biopsy

\begin{tabular}{lll}
\hline Biopsy result & \multicolumn{1}{c}{ Benefit } & Disadvantages \\
\hline Negative (no cancer) & $\begin{array}{l}\text { - No current evidence of prostate } \\
\text { cancer }\end{array}$ & $\begin{array}{l}\text { - The biopsy may have been unnecessary } \\
\text { - Sampling error: existing prostate cancer could be missed } \\
\text { - Prostate cancer could still develop in the future }\end{array}$ \\
\hline $\begin{array}{l}\text { Positive for low-grade (less } \\
\text { aggressive) prostate cancer }\end{array}$ & $\begin{array}{l}\text { - Early treatment can prevent } \\
\text { further illness and the possibility } \\
\text { of related death }\end{array}$ & $\begin{array}{l}\text { - Many tumours grow too slowly to pose any danger during } \\
\text { a lifespan; treatment is therefore unnecessary - but we } \\
\text { cannot tell when this is true }\end{array}$ \\
\hline $\begin{array}{l}\text { Positive for high-grade (aggressive) } \\
\text { cancer (Gleason grade 7-10) }\end{array}$ & $\begin{array}{l}\text { - Early diagnosis and treatment } \\
\text { provides an opportunity for cure }\end{array}$ & $\begin{array}{l}\text { - Cancer could already be incurable at time of diagnosis } \\
\text { - In a few cases, such tumours can still be indolent and } \\
\text { receive treatment that is unnecessary }\end{array}$ \\
\hline
\end{tabular}


This article has been peer reviewed.

From the Department of Urology, University of Texas Health Science Center at San Antonio, San Antonio, Tex.

Competing interests: None declared.

Contributors: Both authors were involved in the conception and design of the study; the acquisition, analysis and interpretation of the data; and drafting and critically revising the article. Both approved the final version to be published.

Acknowledgements: We thank Dr. Dean Troyer for supplying the micrograph images.

This research was supported in part by PHS Cooperative Agreement grant DHHS: UOI CA 86402, awarded by the National Cancer Institute.

\section{REFERENCES}

I. Young HH. The early diagnosis and radical cure of carcinoma of the prostate: being a study of 40 cases and presentation of a radical operation which was carried out in four cases. Bull Johns Hopkins Hosp i905;16:315-2I [reprinted in J Urol 2002;I67(2 Pt 2):939-47 and 2002;168(3):914-2I].

2. Lu-Yao G, Albertsen PC, Stanford JL, et al. Natural experiment examining impact of aggressive screening and treatment on prostate cancer mortality in two fixed cohorts from Seattle area and Connecticut. BMJ 2002;325:740.

3. Andriole GL, Levin DL, Crawford ED, et al; PLCO Project Team. Prostate cancer screening in the Prostate, Lung, Colorectal and Ovarian (PLCO) Cancer Screening Trial: findings from the initial screening round of a randomized trial. J Natl Cancer Inst 2005;97:433-8.

4. Gosselaar C, Roobol MJ, Roemeling S, et al; ERSPC investigators. Screening for prostate cancer without digital rectal examination and transrectal ultrasound: results after four years in the European Randomized Study of Screening for Prostate Cancer (ERSPC). Prostate 2006;66:625-3I.

5. Tarone RE, Chu KC, Brawley OW. Implications of stage-specific survival rates in assessing recent declines in prostate cancer mortality rates. Epidemiology 2000;II: I67-70.

6. Barry MJ. Early detection and aggressive treatment of prostate cancer: groping in the dark. J Gen Intern Med 2000;15:749-5I.

7. Bill-Axelson A, Holmberg L, Ruutu M, et al. Radical prostatectomy versus watchful waiting in early prostate cancer. N Engl J Med 2005;352:1977-84.

8. Feightner JW. The early detection and treatment of prostate cancer: the perspective of the Canadian Task Force on the Periodic Health Examination. JUrol I994;I52:1682-4.

9. So A, Goldenberg L, Gleave ME. Prostate specific antigen: an updated review. Can J Urol 2003;10:2040-50.

Io. Prostate Cancer Alliance of Canada. The early detection of prostate cancer. Can Oncol Nurs J I998;8:262-4

II. Beaulac JA, Fry RN, Onysko J. Lifetime and recent prostate specific antigen (PSA) screening of men for prostate cancer in Canada. Can J Public Health 2006;97:171-6.

I2. McGregor SE, Bryant HE, Brant RF, et al. Prevelance of PSA testing and effect of clinical indications on patterns of PSA testing in a population-based sample of Alberta men. Chronic Dis Can 2002;23:III-9.

I3. Bunting PS, Goel V, Williams JI, et al. Prostate-specific antigen testing in Ontario: reasons for testing patients without diagnosed prostate cancer. $C M A J$ I999;160:70-5.

I4. Mercer SL, Goel V, Levy IG, et al. Prostate cancer screening in the midst of controversy: Canadian men's knowledge, beliefs, utilization, and future intentions. Can J Public Health $1997 ; 88: 327-32$.

I5. Wilson JMG, Jungner G. Principles and practice of screening for disease. Public Health Paper, no. 34. Geneva: World Health Organization; I968.

I6. Cochrane AL, Holland WW. Validation of screening procedures. Br Med Bull I97I; 27:3-8.

17. Sakr WA, Haas GP, Cassin BF, et al. The frequency of carcinoma and intraepithelial neoplasia of the prostate in young male patients. JUrol I993;150:379-85.

I8. American Cancer Society. Cancer facts and figures, 2006. Available: www.cancer .org/downloads/STT/CAFF2006PWSecured.pdf (accessed 2007 Apr 30). Atlanta: American Cancer Society; 2006. p. I3.

I9. Deeks JJ, Altman DG. Diagnostic tests 4: likelihood ratios. BMJ 2004;329:I68-9.

20. Thompson IM, Pauler DK, Goodman PJ, et al. Prevalence of prostate cancer among men with a prostate-specific antigen level of $\leq 4.0 \mathrm{ng}$ per milliliter [published erratum in N Engl J Med 2004;351:1470]. N Engl J Med 2004;350:2239-46.
2I. Begg CB, Greenes RA. Assessment of diagnostic tests when disease verification is subject to selection bias. Biometrics 1983;39:207-I5.

22. Catalona W, Smith D, Ratliff T, et al. Measurement of prostate-specific antigen in serum as a screening test for prostate cancer. $N$ Engl J Med I99I;324:II56-6I.

23. Hodge KK, McNeal JE, Terris MK, et al. Random systematic versus directed ultrasound guided transrectal core biopsies of the prsotate. J Urol I989;I42:71-5.

24. Rabets JC, Jones JS, Patel A, et al. Prostate cancer detection with office based saturation biopsy in a repeat biopsy population. JUrol 2004;172:94-7.

25. Roehrborn CG, Boyle P, Gould AL, et al. Serum prostate-specific antigen as a predictor of prostate volume in men with benign prostatic hyperplasia. Urology 1999;53:58I-9.

26. Stamey TA, Yang N, Hay AR, et al. Prostate-specific antigen as a serum marker for adenocarcinoma of the prostate. N Engl J Med I987;317:909-I6.

27. Guinan P, Bhatti R, Ray P. An evaluation of prostate specific antigen in prostatic cancer. JUrol I987;137:686-9.

28. DeAntoni E, Crawford ED, Stone NN, et al. Prostate Cancer Awareness Week, I992: a summary of key findings. Clin Invest Med I993; 6:448-57.

29. DeAntoni EP; Prostate Cancer Education Council. Eight years of "Prostate Cancer Awareness Week": lessons in screening and early detection. Cancer 1997;80:I845-51.

30. DeAntoni EP, Crawford ED, Oesterling JE, et al. Age- and race-specific reference ranges for prostate-specific antigen from a large community-based study. Urology 1996;48:234-9.

3I. Catalona WJ, Smith DS, Ratliff TL, et al. Detection of organ-confined prostate cancer is increased through prostate-specific antigen-based screening. JAMA 1993;270:948-54.

32. Labrie F, Dupont A, Suburu R, et al. Serum prostate specific antigen as pre-screening test for prostate cancer. JUrol I992;I47:846-5I.

33. Catalona WJ, Smith DS, Ornstein DK. Prostate cancer detection in men with serum PSA concentrations of 2.6 to $4.0 \mathrm{ng} / \mathrm{mL}$ and benign prostate examination. Enhancement of specificity with free PSA measurements. JAMA 1997;277:1452-5.

34. Thompson IM, Goodman PJ, Tangen CM, et al. The influence of finasteride on the development of prostate cancer. N Engl J Med 2003;349:215-24

35. Sokoloff MH, Yang XJ, Fumo M, et al. Characterizing prostatic adenocarcinomas in men with a serum prostate specific antigen level of < $4.0 \mathrm{ng} / \mathrm{mL}$. BJU Int 2004; 93:499-502.

36. Thompson IM, Ankerst DP, Chi C, et al. Operating characteristics of prostate-specific antigen in men with an initial PSA level of 3.0 ng/mL or lower. JAMA 2005;294:66-70.

37. Thompson KE, Hernandez J, Canby-Hagino ED, et al. Prognostic features in men who died of prostate cancer. JUrol 2005;174:553-6.

38. Thompson IM, Ankerst DP, Chi C, et al. Assessing prostate cancer risk: results from the Prostate Cancer Prevention Trial. J Natl Cancer Inst 2006;98:529-34.

39. Phillips TH, Thompson IM. Digital rectal examination and carcinoma of the prostate. Urol Clin North Am I991;18:459-65.

40. Kripalani S, Weinberg AD, Cooper HP. Screening for breast and prostate cancer: a survey of Texas primary care physicians. Tex Med i996;92:59-67.

4I. Thompson IM, Ernst JJ, Gangai MP, et al. Adenocarcinoma of the prostate: results of routine urological screening. JUrol I984;132:690-2.

42. Schroder FH, van der Maas P, Beemsterboer P, et al; Rotterdam section of the European Randomized Study of Screening for Prostate Cancer. Evaluation of the digital rectal examination as a screening test for prostate cancer. J Natl Cancer Inst I998;90:I8I7-23.

43. de Kok JB, Verhaegh GW, Roelofs RW, et al. $\mathrm{DD}_{3}\left(\mathrm{PCA}_{3}\right)$, a very sensitive and specific marker to detect prostate tumors. Cancer Res 2002;62:2695-8.

44. Fradet $\mathrm{Y}$, Saad F, Aprikian A, et al. $\mathrm{UPM}_{3}$, a new molecular urine test for the detection of prostate cancer. Urology 2004;64:3II-5.

45. Catalona WJ, Partin AW, Slawin KM, et al. Use of the percentage of free prostatespecific antigen to enhance differentiation of prostate cancer from benign prostatic disease: a prospective multicenter clinical trial. JAMA I998;279:1542-7.

46. Adam BL, Qu Y, Davis JW, et al. Serum protein fingerprinting coupled with a pattern-matching algorithm distinguishes prostate cancer from benign prostate hyperplasia and healthy men. Cancer Res 2002;62:3609-I4.

47. Ross PL, Gerigh C, Gonen M, et al. Comparisons of nomograms and urologists' predictions in prostate cancer. Semin Urol Oncol 2002;20:82-8.

48. Parekh DJ, Ankerst DP, Higgins BA, et al. External validation of the Prostate Cancer Prevention Trial risk calculator. Urology 2006;68:II52-5.

Correspondence to: Dr. Ian Thompson, Department of Urology, The University of Texas Health Science Center at San Antonio, 7703 Floyd Curl Drive, San Antonio TX 78229; fax 210 567-6868; thompsoni@uthscsa.edu 